\title{
Application of Virtual Reality Technology in Complex Warfare Field
}

\author{
Kang Wang ${ }^{\text {a }}$, Guiqing Gao, Yuanli Qin and Jingjing Zhang \\ Xi'an High-tech Research Institute, Xi'an Shannxi ,710025, China \\ a441974661@qq.com
}

\begin{abstract}
In order to strengthen the study of complex war issues in the era of intelligence, the idea of using virtual reality technology as a bridge to connect artificial intelligence and complex warfare is proposed. By analyzing the characteristics, classification, and development of virtual reality technology, the application of virtual reality technology in the construction of a complex war system, the construction of a virtual battlefield environment, and the construction of military training conditions in the military field is summarized. A preliminary discussion on the issues surrounding the excavation of winning factors in the field of virtual reality, accelerating the advancement of core technology research, and promoting the standardization of the virtual reality field is carried out.
\end{abstract}

Keywords: virtual reality, intelligent, complex warfare, model, military training.

\section{Introduction}

Virtual reality technology is the quintessence of human wisdom and technological progress. It was founded on the breakthrough of computer technology, computer graphics, multimedia technology, sensor technology, display technology, human-computer interaction theory, and artificial intelligence. It innovated the way of communication between people and computers, and gradually changed the way of life of human beings. The advanced technology always takes the lead in serving the military field. The value of virtual reality technology in the military field is getting more and more attention from all countries. Especially in recent years, the development of artificial intelligence technology is changing with each passing day, and it has become more and more obvious that it has become a major factor in changing the form of war. Strengthen virtual reality technology and application research in the military field, in order to give full play to the role of virtual reality technology in linking artificial intelligence with complex warfare. It is of great significance to accurately discover the winning factors of complex wars in the era of intelligence, grasp the winning mechanism in depth, enhance the operational effectiveness of the system, and win complex wars.

\section{Virtual Reality Technology Introduction}

Virtual Reality (VR) technology is a newly integrated technology in the 1980s. It refers to the use of modern high technology with computer technology as the core to generate realistic visual, auditory, and haptic virtual reality. The user interacts with the objects in the virtual world in a natural way with the necessary equipment to create a feeling and experience in the real environment [1].

\subsection{The Connotation and Extension of Virtual Reality Technology}

"Virtual" means that the computer-generated world, environment, and various models are virtual and exist in the computer's internal world. Humans enter the virtual world through human-machine interfaces and carry out corresponding activities. "Reality" refers to the construction of the virtual environment based on the real world, which is an objectively existing map that truly reflects the basic composition and various attributes of the real environment. Virtual reality is to create a new environment that one can enter through various technical means and create a strong sense of reality, enabling people to carry out various activities in the real world in the virtual world. 


\subsection{The Main Features of Virtual Reality Technology}

American scientist Burdea G. published an article entitled "Virtual Reality systems and Applications" at the World Electronics Conference in 1993, which for the first time proposed three characteristics of virtual reality technology, namely: Interaction, immersion and imagination, or "3I" Feature [1]. Interaction refers to the fact that users can naturally interact with objects in the virtual environment and reflect the natural and real-time degree of their operational level and feedback from the virtual environment. Immersion is the most important feature of virtual reality technology, it makes users as protagonists in the virtual environment, allowing users to become direct participants, feeling that they are part of the virtual environment created by computer systems, and being able to fully immerse themselves in virtual Practice. Imagination refers to the ability of the user to reproduce the real environment in virtual reality, and to conceptualize its future progress through logical thinking, thrust and association, and other thought processes as the system's operating status changes.

\subsection{Classification and Application of Virtual Reality System}

The virtual reality system is an organic combination of virtual reality technology and equipment. Users can enter the virtual world with virtual reality systems and can be divided into immersive virtual reality, enhanced virtual reality and hybrid virtual reality systems. Among them, the enhanced virtual reality system can realize the superposition of computer-generated perception information and the physical real world, realizing integration of the real world and the virtual world in three-dimensional space, mainly through a system based on a monocular display, a system based on a see-through helmet display, and the like. achieve.

As the development of virtual reality technology and related disciplines continues to mature, its functions have been continuously improved and gradually applied to military, medical, education, industrial design and other fields. Especially in the military field, the U.S. military has taken the lead in integrating it with real-time distribution systems and human-machines. The combination of theory and technology in interactive systems, psychology, and other related fields applies to military training and exercises, weapon system design and assessment, and personnel psychological intervention, which have brought tremendous benefits [2-3].

\section{Virtual Reality Technology Lays the Foundation for Winning Complex Wars}

Strengthening the application research of virtual reality technology, especially how to use virtual reality technology to construct a complex war system and simulate the battlefield environment, and further optimize the enrichment of training methods is of great significance for enhancing the ability to win future complex wars.

\subsection{Building Complex War System}

Complexity refers to the complex intertwining or interconnection between a system's internal unit and its environment. The combat system refers to the organic whole formed by various combat systems according to certain command relationships, organizational relationships, and operational mechanisms [4]. According to the complexity theory, since the joint operations system is a system composed of many interacting units and many different levels, its composition, structure, behavior, evolution, and status are full of features such as autonomy, adaptability, and uncertainty. It is possible to simplify its overall behavior into a geometry that consists of the characteristic properties of a single unit and therefore necessarily belongs to a complex system. For the construction of a complex system model, it is necessary to accurately establish the entity unit model, relationship model and interaction model. The physical model refers to the actual combat units involved in the war, including troops, personnel, weapons and equipment, and materials and equipment, which constitute the material basis of the combat system. The relational model is used to describe the relationship between the entity models, and to clarify issues such as command relationships and affiliation relationships. The interaction model refers to the effects produced by the interaction between the entity model and the entity model, the entity model and the environment model. The various effects and influences on the 
entity are the core of the success or failure of the system model construction. The construction of the system model should be based on the rational formulation of the rules, and the "coupling, coordination, and synchronization" coupling index should be introduced. The establishment of the entity model should fully consider the formation of troops and wartime formation. The establishment of the relationship model must comply with the command principle and the interaction model. We must respect the theory of materialist dialectics, make full use of the ideology of connection, contradiction, and movement, and establish a horizontal and vertical relationship grid based on objective data collection and simulation calculations, so as to build an objective and realistic model of a complex war system.

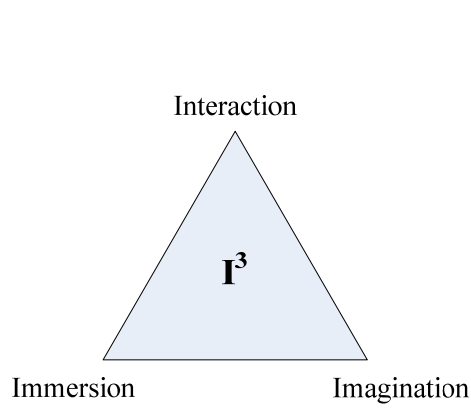

Figure 1. Virtual Technology's "3I" Features

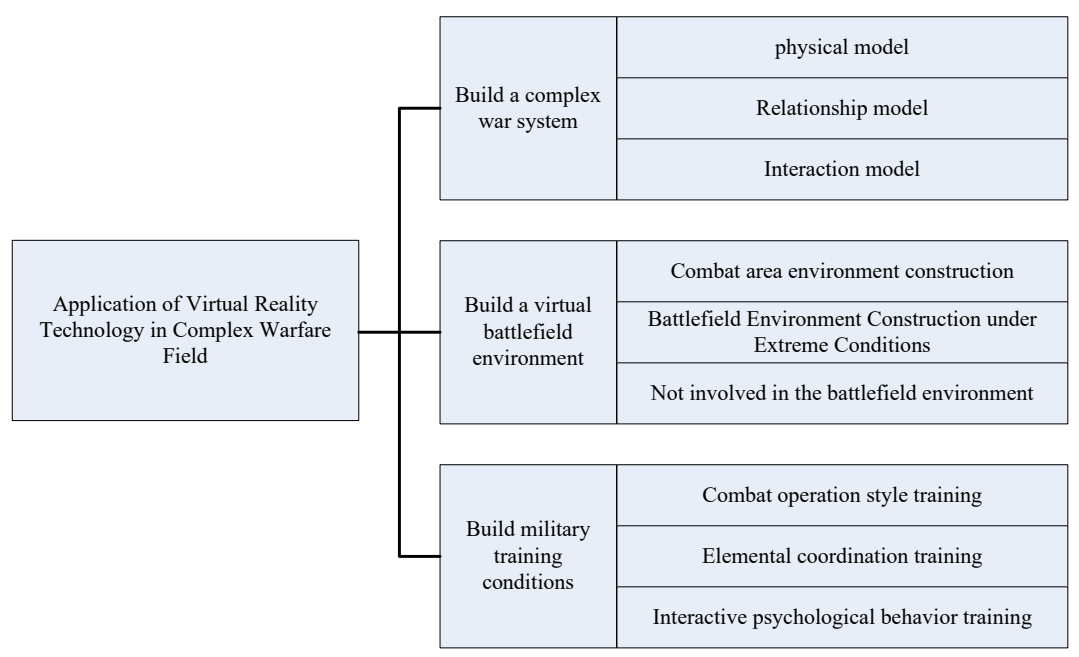

Figure 2. Application of Virtual Reality Technology in Complex Warfare Field

\subsection{Building Virtual Battlefield Environment}

The construction of the battlefield environment is achieved through the battlefield environment model. The battlefield environment model refers to the mode of data representation through the analysis and abstraction of the natural environment within the space of the battle area and describes and represents the natural environment in the form of data according to this model. The various objects and methods and processes in the entity include the land, sea, air, sky, electromagnetic environment, and operational opponents in the combat zone. By simulating the battlefield environment, seamless integration and peer mapping between the actual battlefield and the virtual battlefield are realized, which provides guarantees for improving the quality of joint operations training. The construction of virtual battlefield environment should fully consider the characteristics of fast warfare, multiple dimensions of confrontation, and three-dimensionality of combat area in complex warfare in the future. The main battlefield modeling, extreme conditional environment modeling and battlefield environment modeling in the unattended field shall be carried out. Conduct battlefield environment modeling in major combat areas. In view of the typical combat operations that China may participate in in the future, based on the Joint Operational Action Plan, the battlefield environment elements and combat data collection work will be carried out. After processing, screening, and standardization, the virtual battlefield environment in the main battle area will be constructed. Conduct combat training to provide protection. Perform environmental modeling under extreme conditions. Strengthen the analysis of the enemy's situation and the means of combat capabilities, aiming at realizing the possibility of high-intensity interventions, nuclear strikes, saturation attacks, rapid strikes, and critical strike points and strategic targets hitting the enemy precisely in future operations. The extreme environment was constructed to provide support for effective combat under extreme conditions. Not involved in battlefield modeling. In view of future areas that may be vigorously seized by the countries and cannot be fully involved at this stage, such 
as deep sea, space, cyberspace, etc., we must strengthen research on operational issues in frontier areas, actively develop virtual environments, and strive to seize strategic opportunities.

\subsection{Building Military Training Conditions}

The joint practice drills use many military equipment, and the organization has a long period of time and is difficult to implement. The construction of military training conditions based on virtual reality technology makes it possible to conduct joint operations training in normal conditions, strengthen the perception of officers and soldiers on the battlefield, and greatly improve the quality of training. Cure typical combat style tactical actions. During the war of liberation, Chairman Mao used "you fight in your way, I fight in my way" to vividly summarize our strategy and tactics. We have a deep understanding of the contradictory categories of strong and weak, active and passive, and offensive and defensive. The specific application of this ideological spirit is to take the initiative to carry out the design of complex warfare forms in the intelligent era and to carry out advanced combat operations training in the future through virtual reality technology, so as to optimize force preparation, straighten out command relationships, and verify operational capabilities, overcoming difficulties. Because of the unfavorable effects of institutional restructuring and changes in the operational command relationship, the operational capability of the military is steadily improved. Conduct collaborative training of various elements. The multiple elements of war, the scattered deployment of troops, the fast pace of war, and the changing battlefield conditions are important features of complex warfare. Distributed virtual reality systems are used to bring all the elements of the war into the same virtual space, and to achieve simultaneous coordination and coordination training for different military units. Specialized scouring is performed for key nodes such as command relationships, coordination opportunities, and fire distribution in coordinated operations. Psychological and behavioral training. By preliminarily setting up a realistic battlefield environment, officers and men are fully immersed in the virtual battlefield environment. Through the detection and evaluation system for a number of physiological indicators, psychological status assessments are conducted to find hidden dangers of psychological diseases, thus psychological evaluation and personnel screening are performed. at the same time, by setting up virtual psychological counselors, psychological interventions are performed on officers and soldiers according to the situation in the virtual scene to enhance their emotional management and coping ability under stress conditions [5].

\section{Reflections on Strengthening the Application of Virtual Reality Technology}

Virtual reality technology is still a relatively new thing for our military and has not been practiced too much. Strengthening the application of virtual reality technology in the military field should always focus on the theme of exploring the winning factors and winning mechanism of complex wars, strengthen the core technology research, and establish a standard system as soon as possible so as to achieve long-term benefits.

\subsection{The Application of Virtual Reality Must Always Focus on the Core of the Winning Factor}

To explore the winning factors of war is the basis for winning all wars. The joint operations in the era of intelligence are inevitable in the development of informatized warfare. The entry of intelligent technologies into the field of military operations has led to intelligent warfare. Intelligent factors have been integrated into the complex warfare system as a core factor to create intelligence and are built upon the fusion of multi-source information acquisition. Based on intelligence, winning will replace information as its most significant feature. As the center of the intelligent combat system, intelligent power dominates the function of other elements and becomes the basis for the existence and development of the combat effectiveness of the armed forces in the intelligent era. Countries with obvious advantages in intelligence can make full use of asymmetric advantages to maximize freedom of movement on the battlefield, gain significant advantages in battlefield awareness, command and control, weaponry, and combat effectiveness, and achieve effective control of the battlefield. To grasp the initiative of joint operations in the era of intelligence, the research, development, and application 
of virtual reality must always highlight the important factor of intelligence. It must be based on tapping the winning factors of intelligent and complex wars and exploring the winning mechanism.

\subsection{Accelerating Key Technology Research to Solve Real Needs}

The key technologies of virtual reality include three-dimensional display technology, multiperceived natural interaction technology, environment modeling technology, and real-time rendering technology. The three-dimensional display technology includes polarized light splitting 3D display, image color separation stereo display, Dolby image color separation, time-sharing display, HMD helmet display technology, and the like. The multi-sensory natural interaction technologies include motion capture technology, 3D light sensing technology, eye tracking technology, voice interaction technology, tactile technology, sense of smell, and other sensory interaction technologies. The virtual environment modeling technology is the core of virtual reality technology, including threedimensional geometric modeling, physical modeling and behavior modeling, respectively describing the geometric information of the object, the motion properties of the model and the processing and behavior of the object movement. The real-time rendering technology mainly uses a virtual reality engine to generate results using 3D holographic projection and other devices after real or virtual scenes, tasks, and object models obtained through the environment modeling technology. However, the modeling techniques for virtual environments and geometric models are still at a preliminary stage of exploration, and the analysis and evaluation of interactive influences and the setting of rules are still insufficient. Stereo display, and tactile, olfactory and other behavior-awareness and interactive expressions are still relatively single. There is still a big gap between fully simulating the human perception system. At the same time, with the continuous manifestation of the influence of artificial intelligence on future complex wars, the characteristics dominated by intelligence in future complex wars will become even more pronounced. There are still significant technical obstacles in achieving a direct connection between the human brain and computers and direct exchange of two-way information.

\subsection{Promote Standardization in the Field of Virtual Reality to Pursue Long-Term Benefits}

The realization of virtual reality relies on huge battle data and various types of models, and it requires significant human, material and financial resources and advanced technological means to realize it. Compared with other training methods, the virtual reality system is more as an auxiliary means of environmental shaping, and its essential attributes determine that it must be organically combined with the war chess system, simulation training equipment, and integrated drills of soldiers to make it more effective. Big benefits. Therefore, we must establish a standardization work in the field of virtual reality, establish a unified data collection standard, model development standards, judgement and adjudication standards, and regulate the development of virtual reality from the source to achieve the principle of optimal cost-effectiveness. In the context of the accelerated evolution of war forms, the main rivals' new concept tactics and the frequent deployment of equipment, and the rebuilding of our military command system, we will accelerate the integration of military and civilian in the field of virtual reality and encourage local companies with significant technological advantages to enter the military field and advance. The technology has led the leap-forward development of the field of military virtual reality, achieving the purpose of constructing a combat system, practicing an action program, enhancing combat capabilities, and consolidating the tactics of war. It is of great significance for our military to win joint operations in the era of intelligence.

\section{References}

[1]. A Weihua. Virtual reality technology and its application [M]. Beijing: Tsinghua University Press, 2014: 7.

[2]. Li Xinhui, Chen Meilan. Virtual reality technology and its application [M]. Beijing: Tsinghua University Press, 2016: 9-13. 
[3]. A Xing, Li Gang, Xu Linwei, et al. Application and development of virtual reality technology in US military simulation training[J]. Electro-Optics \& Control:2011,18(10):42-46.

[4]. Qiao Jie, Zeng Chufeng. To build an information-based combat system must strengthen the construction of information support system [J]. Military Academy: 2014, 7: 66-68.

[5]. Chen Yongke, Yu Jie. Application of Virtual Reality Technology in Wartime Psychological Training System [J]. Journal of Ordnance Equipment Engineering, 2017, 6:161-164. 